OnLine Journal of Biological Sciences 8 (2): 41-43, 2008

ISSN 1608-4217

(C) 2008 Science Publications

\title{
Prey-Catching Behaviour in Mudskippers and Toads: A Comparative Analysis
}

\author{
U. Kutschera, H. Burghagen and J.-P. Ewert \\ Institute of Biology, University of Kassel, Heinrich-Plett-Str. 40, D-34109 Kassel, Germany
}

\begin{abstract}
The invasion of land by a diverse group of fishlike amphibians during the Middle-Late Devonian was a key event in the history of life. It is obvious that the evolutionary transition from an aquatic to a terrestrial habitat was associated with physiological adaptations such as novel feeding strategies that can not be elucidated with fossils alone. Here we show that two extant vertebrate species, an amphibious fish (the Atlantic mudskipper Periophthalmus barbarus L.), and the common toad (Bufo bufo L.), which both feed on earthworms, have evolved the same modes of prey recognition. In double-choice experiments, both the fish and the tetrapod tried to capture a moving black bar in worm configuration; a vertical (anti-worm) stimulus did not elicit such a response. This finding sheds light on events that may have occurred in semi-aquatic habitats over 370 million years ago.
\end{abstract}

Key words: Convergent evolution, mudskippers, prey catching

\section{INTRODUCTION}

Mudskippers are air-breathing gobies (subfamily oxudercinae) that inhabit the areas in and around the mangrove swamps and intertidal regions of Africa, Asia and Australia. They have evolved special anatomical adaptations, such as arm-like side fins, that help them to "skip" over the mud. Some species spend more time on land than in water and climb trees. Like in frogs and toads, their eyes are perched high on the head, enabling them to see potential food organisms and to avoid birds, which prey on these amphibious fishes ${ }^{[3,5]}$.

In a classical study, Stebbins and Kalk ${ }^{[8]}$ described the behaviour of the mudskipper Periophthalmus argentilineatus (syn.: P. sobrinus) on Inhaca Island, East Africa. During these field studies, the authors "spent many hours watching feeding" and described these observations in detail. Under natural conditions, P. argentilineatus appears to primarily seek food on land. Colombini et al.$^{[3]}$ corroborated and extended these field observations on populations of the same species.

In a laboratory study, the terrestrial feeding behaviour of the Atlantic mudskipper (Periophthalmus barbarus L. 1766) was examined by light and $\mathrm{x}$-ray cinematography ${ }^{[7]}$. The authors describe anatomical specializations of the pharyngeal jaws and report that multiple terrestrial feedings occur without a return to the water. However, the mode of prey recognition was not analyzed.

Studies on amphibians led to the hypothesis that visually guided feeding behaviour, with a moving prey organism in horizontal ("worm-like") position, may be a key adaptation for the survival on land ${ }^{[4]}$. In this investigation we compare the mode of terrestrial prey capture in mudskippers with that of the common toad and discuss the results with respect to the transition from water to land during tetrapod evolution in the Middle-Late Devonian ${ }^{[1]}$.

\section{MATERIALS AND METHODS}

Juvenile Atlantic mudskippers (Periophthalmus barbarus Linnaeus 1766, syn. P. koelreuteri Pallas 1770 , body length $36-48 \mathrm{~mm}$ ) were purchased from a commercial dealer and kept in aqua-terraria under a $12 \mathrm{hr}$ light/dark cycle (lights on at 8:00 a.m.) at a temperature of $25 \pm 1^{\circ} \mathrm{C}$. The depth of the water was ca. $5 \mathrm{~cm}$; dry sandy regions above the water and rocks provided land areas for these amphibious vertebrates. The mudskippers were fed on oligochaetes (Lumbricus castaneus, Tubifex tubifex) and house crickets (Gryllus domesticus). The preycatching behaviour of two mudskippers of average size was recorded with a video camera. Common European toads (Bufo bufo L.) were maintained in terraria as described by Ewert ${ }^{[4]}$ and received the same prey organisms as the mudskippers.

Corresponding Author: Institute of Biology, University of Kassel, Heinrich-Plett-Str. 40, D-34109 Kassel, Germany. 
Prey-selection experiments were conducted on both species in a glass container $(20 \times 30 \times 20 \mathrm{~cm})$ as shown in Fig. 1 (white light, temperature and relative humidity of $25 \pm 1{ }^{\circ} \mathrm{C}$ and $80 \pm 5 \%$, respectively). The subjects (14 mudskippers and 20 toads) were not fed over the past 3 days. Within a transparent window, a motor-driven mechanical device allowed the experimenter to present two visual stimuli to the fish (or toad), which had left the water to wait in a defined position. Stimuli (two black rectangular bars of 1 x $6 \mathrm{~mm}$ (mudskippers) or $2.5 \times 20 \mathrm{~mm}$ (toads), respectively) were moved simultaneously in opposite directions at $5 \mathrm{~mm} / \mathrm{s}$ over a distance of $8 \mathrm{~cm}$ in a worm or anti-worm configuration, see arrows in Fig. 1. The reaction of the animal was recorded over the subsequent 2 min with a video camera. All qualitative observations were repeated at least three times on the same subject.

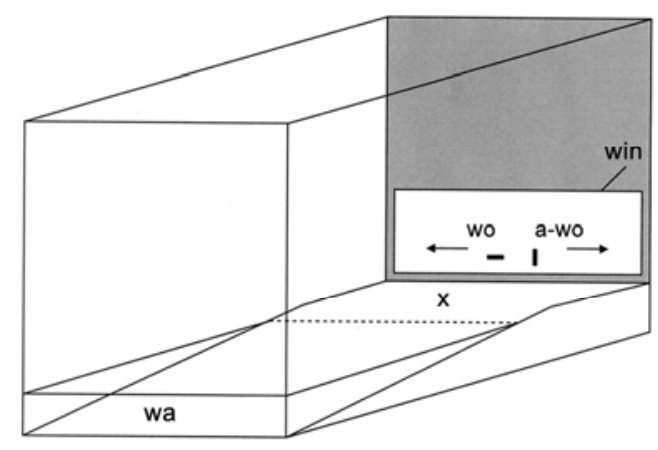

Fig. 1: Glass container $(20 \times 30 \times 20 \mathrm{~cm})$ for doublechoice experiments. The visual stimuli were presented simultaneously. wa $=$ water, win $=$ transparent window, wo $=$ worm configuration, a-wo $=$ anti-worm configuration, $\mathrm{x}=$ position of the mudskipper or toad.

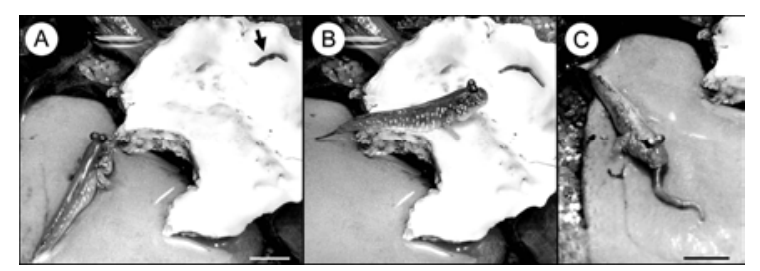

Fig. 2: Prey capture by a juvenile Periophthalmus barbarus out of water. The amphibious fish detects the earthworm (arrow) (A), approaches it and watches its prey (B). Within less than one minute, the mudskipper captures the worm and swallows it on land (C). Scale bars $=1 \mathrm{~cm}$.

\section{RESULTS AND DISCUSSION}

All P. barbarus individuals analyzed in this study detected potential prey organisms entirely by sight. Since in the stomach of free-living mudskippers digested annelids were found ${ }^{[8]}$, we used small earthworms (Lumbricus castaneus) as food organisms. Following visual detection of a worm on land, the fish rapidly propels itself out of the water using the pectoral and caudal fins (Fig. 2 A, B). Thereafter, the prey organism is rapidly captured and swallowed on land (Fig. 2 C).

Is prey-recognition in P. barbarus adapted to terrestrial food organisms that move in a worm-like fashion? Using artificial stimuli we analyzed whether or not a black bar oriented parallel to the direction of movement ("worm") can be distinguished from a bar oriented across the direction of movement ("antiworm") and compared this behaviour with results observed in common toads.

The principle of the experimental double-choice procedure, where two bars (in worm and anti-worm configuration, respectively) are moved simultaneously from the centre of a window in opposite horizontal directions, is illustrated in Fig. 1. The amphibious fish usually waited on the moist substrate $35-50 \mathrm{~mm}$ from the test stimuli. In 48 double-choice tests with 14 individually marked mudskippers, at 42 times the worm configuration and 6 times the anti-worm configuration was pursued (positive reaction of the amphibious fish within 1 min). Each stimulus was presented either to the left or right side so that preferences for one stimulus side were equalized. On average, the worm- to anti-wormpreference was significant $(\mathrm{P}<0.01$; sign test). In response to the anti-worm stimulus the mudskippers raised their dorsal fin which signals aggression. Hence, the approach towards this stimulus can be interpreted as an agonistic act of the animal ${ }^{[4,5]}$. Dorsal fin erection was not observed during feeding episodes (Fig. $2 \mathrm{~A}-\mathrm{C}$ ) and when the fish was challenged by the worm-like stimulus in our behavioural testing apparatus (results not shown).

Our corresponding experiments with toads yielded the following results. All 20 B. bufoindividuals tested in the double-choice procedure (Fig. 1) selected the black bar in worm configuration. All amphibians pursued this visual stimulus and 16 toads snapped at it one to three times. The moving bar in anti-worm configuration was ignored by all 20 toads. Hence, in our double-choice procedure, toads always decided in favour of the worm stimulus. The worm to anti-worm preference was independent of previous prey experience ${ }^{[4]}$. 
It has been postulated that visually guided feeding opportunities on land are imperative for the survival of amphibious tetrapods ${ }^{[4]}$. Our experimental finding that both mudskippers (gobioid fishes) and toads (amphibians) choose the worm (vs. the antiworm) configuration and react to this stimulus as if it would be a food organism may be interpreted as convergent evolution in prey-catching behaviour of a fish and a tetrapod, probably owing to similar selection pressures. The evolutionary lineages of these vertebrates diverged more than 400 million years ago ${ }^{[2,5]}$.

\section{CONCLUSIONS}

We conclude that mudskippers are living model organisms suitable for the study of the evolutionary transition from water to land ${ }^{[1,6]}$. These modified fishes "out of water" have evolved amphibian-like adaptations and behaviours that enable them to forage on moist soil and hence to exploit a novel terrestrial habitat that is hostile to their aquatic ancestors.

\section{ACKNOWLEDGMENTS}

We thank colleagues for helpful comments on an earlier version of the manuscript and the Bundesministerium für Wissenschaft und Technology (Fkz. 03 ESFHE 021) for financial support.

\section{REFERENCES}

1. Ahlberg, P.E. and J.A. Clack, 2006. A firm step from water to land. Nature, 440: 747-749.

2. Clayton, D.A., 1993. Mudskippers. Oceanogr. Mar. Biol. Rev., 31: 501-577.

3. Colombini, I., R. Berti, A. Nocita and L. Chelazzi, 1996. Foraging strategy of the mudskipper Periophthalmus sobrinus eggert in a kenyan mangrove. J. Exp. Biol. Ecol., 197: 219- 235.

4. Ewert, J.P., 2004. Motion Perception Shapes the Visual World of Amphibians. In: Complex Worlds from Simpler, Nervous Systems. Prete, F.R., (Ed.). MIT Press, Cambridge, pp: 177-260.

5. Graham, J.B., 1997. Air-Breathing Fishes. Evolution, Diversity, and Adaptation. Academic Press, New York.

6. Kutschera, U., 2006. Mudskippers undermine ID claims on macroevolution. Nature, 439: 534.

7. Sponder, D.L. and G.B. Lauder, 1981. Terrestrial feeding in the mudskipper Periophthalmus (Pisces: Teleostei): A cineradiographic analysis. J. Zool. London, 193: 517-530.

8. Stebbins, R.C. and M. Kalk, 1961. Observations on the natural history of the mud-skipper Periophthalmus sobrinus. Copeia, 1961: 18-27. 